\title{
The Tripartite Model of Neuroticism and the Suppression of Depression and Anxiety Within an Escalation of Commitment Dilemma
}

\author{
Henry Moon \\ Robert H. Smith School of Business University of Maryland
}

\author{
John R. Hollenbeck \\ Stephen E. Humphrey \\ Brian Maue
}

Michigan State University

\begin{abstract}
We found evidence of a mutual suppression effect between anxiety and depression on an individual's level of commitment within escalation dilemmas. On the one hand, our results demonstrate a positive relationship between anxiety and level of commitment; on the other, our results demonstrate a negative relationship between depression and level of commitment. Based on the opposing relationships between anxiety and depression and commitment, the broad factor of neuroticism does not demonstrate any relationship with level of commitment, and the significant effects of anxiety and depression on commitment is contingent upon partialling the effect of the other facet of neuroticism. Thus, we contend that applied psychologists, who have focused on neuroticism as a broad construct, should consider the large body of work among clinical

Correspondence concerning this article may be sent to: Henry Moon Robert H. Smith School of Business, University of Maryland, College Park, MD 20742-1815. (301) 4054708.hmoon@rhsmith.umd.edu

Grant N00014-96-1-0983 from the Cognitive and Neural Sciences Division of the Office of Naval Research supported this research. Although support for this work is gratefully acknowledged, the ideas expressed herein are those of the authors and not necessarily endorsed by the funding agency.
\end{abstract}

Journal of Personality 71:3, June 2003.

Copyright (C) 2003 Blackwell Publishing. 
psychologists, who argue that anxiety and depression have unique variance associated with them. We conclude by addressing organizational implications of measuring the broad trait of neuroticism more narrowly.

Over the past decade, the perceived utility of using personality constructs to predict organizational criteria of interest has been on the rise (Mount \& Barrick, 1998). The increase in attention afforded to personality-based studies can, in part, be attributed to a confluence between increasing consensus on a broad taxonomy of personality traits (Digman, 1990; Goldberg, 1992) and metaanalyses tying these traits to organizational criteria (Barrick \& Mount, 1991; Hough, Eaton, Dunnette, Kamp, \& McCloy, 1990; Hurtz \& Donovan, 2000; Tett, Jackson, \& Rothstein, 1991). The personality factor that has demonstrated the most consistent relationship with job-related criteria, and received the most attention, has been conscientiousness. Recent research has tied conscientiousness to both individual (e.g., Colquitt \& Simmering, 1998) and group (e.g., Barrick, Stewart, Neubert, \& Mount, 1998; Lepine, Hollenbeck, Ilgen, \& Hedlund, 1997; Neuman \& Wright, 1999) level outcomes.

Salgado (1997) and Hurtz and Donovan (2000) recently conducted follow-up meta-analyses wherein they not only confirmed the positive relationship between conscientiousness and job performance, but also demonstrated a broad negative relationship between neuroticism (low emotional stability) and job-related criteria. Therefore, meta-analytical evidence exists of a broad personality trait that predicts positive job performance (conscientiousness) and another broad personality trait that predicts negative job performance (neuroticism). In fact, Salgado has gone as far as to conclude, "the estimated true validity for emotional stability (measured as the inverse of neuroticism) has a size very close to that for conscientiousness. Moreover, as in the case of conscientiousness, the validity of emotional stability is generalizable across jobs and criteria" (Salgado, 1997, p. 36).

Neuroticism has a long history of attention from both classical psychologists (Freud 1930; Horney 1937; 1945) and classical personality researchers (Fiske, 1949; Norman, 1963). Among organizational researchers, neuroticism has been conceptualized as a lack of emotional stability (Goldberg, 1993), emotional control 
(Fiske, 1949), adjustment (Hogan \& Hogan, 1992), and ego strength (Digman \& Takemoto-Chock, 1981). In fact, Mount and Barrick (1995) assert that one of the first large-scale uses of personality (the Woodworth Personality Data Sheet) was during the First World War, and it was limited to discerning those who were susceptible to wartime stress.

Although the potential value of having two generalizable broad personality variables is enticing, a closer examination of the neuroticism construct is warranted. First, in spite of the positive results obtained by Salgado (1997), a recurring problem with the broad construct of neuroticism has been its uniformly low predictive ability on organizational criteria of interest (Barrick, Mount, \& Judge, in press; Hurtz \& Donovan, 2000). Barrick, Mount, and Judge recently summarized previous personality meta-analyses and found that the neuroticism construct was distinguishable from zero, but its effect size was surprisingly low. Second, outside of the FiveFactor framework, it is commonly accepted among clinical psychologists that neuroticism is comprised of at least two relatively independent dimensions (anxiety and depression), not one (Clara, Cox, \& Enns, 2001; Clark \& Watson, 1991). Moreover, the nature of these two components suggests that they might be differentially related to various kinds of behaviors or decision making that occur in organizational contexts.

The purpose of this paper is to discuss two different facets of neuroticism and demonstrate their discriminant validity in the context of a common organizational research paradigm. The central tenet of this manuscript, that facets of personality provide better explanatory power than do the broad factors, extends the growing body of literature extolling the utility of a narrower conceptualization of personality (Ashton, 1998; Hough, 1992; Paunonen \& Ashton, 2001; Paunonen \& Jackson, 2000). Paunonen, Rothstein, and Jackson (1999) note that, in addition to the superior predictive power of narrow traits, the broad factors hinder the psychological meaningfulness and interpretability of personality-job performance relationships. We advance the recent string of research regarding narrow facets of personality, but instead of advocating the superior predictive ability of narrow facets, we demonstrate a context wherein the narrow facets underlying a broad factor have opposite predictive ability. 
More specifically, we will distinguish between anxiety and depression, which the current Five-Factor Model treats as facets within a single factor, and demonstrate their differential relationship to a widely studied organizational decision-making bias (i.e., escalation of commitment dilemmas). For reasons discussed more fully below, escalation of commitment is likely to be more prevalent among people high in anxiety relative to those who are low in anxiety. However, at the same time, escalation of commitment is likely to be less pervasive among people who are high in depression relative to those who are low in depression.

If one fails to make this distinction, the mutually suppressing effects of anxiety and depression on escalation of commitment will lead one to conclude that neuroticism is unrelated to escalation of commitment, when, in fact, it is a critically important predictor. In fact, the differences inherent at the facet level of neuroticism provide an alternative reason for the depressed relationship between the broad factor neuroticism and organizational criteria. We will argue that, outside of the narrow realm of escalation of commitment, applied organizational researchers would be wise to heed the distinction between anxiety and depression and not fall prey to the single-factor interpretation of neuroticism that is embodied in the increasingly popular Five Factor Model framework.

\section{THEORY AND HYPOTHESES}

\section{The Tripartite Model of Neuroticism}

Costa and McCrae (1992), authors of the most widely used fivefactor personality instrument, define their measure of neuroticism in broad terms as "the general tendency to experience negative affects such as fear, sadness, embarrassment, anger, guilt and disgust. Men and women high in $N$ are also prone to have irrational ideas, to be less able to control their impulses, and to cope more poorly than others with stress" (p. 14).

Early organizational scientists concerned with personality (Cattell, 1947; 1956; Norman, 1963; Tupes \& Christal, 1961) defined neuroticism close to definitions of anxiety. Recent researchers have expanded the definition of neuroticism to include elements of depression (Costa \& McCrae, 1985; Hogan, 1983; John, 1989). These two facets of neuroticism have received a great deal of 
attention from clinical psychologists and personality researchers (Clark \& Watson, 1991; Kremen, 1996; Mendels, Weinstein, \& Cochrane, 1972; Stavrakaki \& Vargo, 1986). Clark and Watson (1991) summarized a large body of literature concerning these two constructs and assert that anxiety and depression have both shared and unique variance components. This led to a "tri-partite" model conceptualization where the shared component of general affective distress (broad Neuroticism) is recognized, along with two mutually exclusive variance components unique to anxiety and depression. A comprehensive review of various scales related to anxiety and depression led Clark and Watson to the conclusion that positive affect was a distinguishing characteristic of the two facets. Specifically, Clark and Watson asserted that although both anxiety and depression were related to high levels of negative affect, depression alone was strongly associated with a general lack of positive affect. Costa and McCrae (1992) defined anxious individuals along the lines of those individuals who are apprehensive, fearful, nervous, tense, and jittery. They viewed depressed individuals as those who are "easily discouraged and often dejected" (p. 16). Clara, Cox, and Enns (2001) have recently supported the tripartite model of neuroticism via confirmatory factor analysis. Wetherell, Gatz and Petersen (2001), using a longitudinal design, demonstrated that a model with distinct anxiety and depression components better explained the mental health of a mature sample.

The unique difference between anxiety and depression is best exemplified by Beck's $(1967,1976)$ cognitive theory. According to Beck, the crucial difference between anxiety and depression is in how they influence the cognitive process of the individual. On the one hand, thoughts of loss and failure dominate the cognitive process of depressed individuals. On the other, cognition related to harm and danger dominates the stream of consciousness of those individuals high in anxiety. Although the difference between anxiety and depression has been demonstrated within a clinical setting, there has been little attention given to how these two subfactors of neuroticism might be important in an organizational context. Further, among organizational scientists, little theory has been provided for why the narrow facets of depression and anxiety might be superior predictors of behavior than the broad factors of neuroticism. We present the large body of decision-making literature concerned with the propensity for individuals to escalate their 
commitment to losing courses of action as a means of demonstrating the superior predictive ability of the narrow facets of neuroticism over the broadly measured factor.

\section{The Tripartite Model and Escalation of Commitment}

In a recent review, Staw (1997) argued that the tendency to escalate one's behavior to losing courses of action is a ubiquitous decision error. These escalation dilemmas have three requirements. First, they are situations wherein a large amount of resources has already been invested. Second, in spite of past expenditures, the performance of the project has not met expectations or is actually in danger of failing. Third, the previous two requirements place decision makers in a dilemma wherein they must either continue with the initial decision or abandon the project. Escalation of commitment has been explored in a wide variety of settings and this decision-making error has been blamed for the loss of thousands of lives and billions of dollars (McNamara, Moon, \& Bromiley, in press; R. S. McNamara \& VanDeMark, 1995; Ross \& Staw, 1993). Therefore, the extent to which individuals are able either to extract themselves from losing positions or are prone to fall victim to escalation biases is important for organizations (Simonson \& Staw, 1992).

Traditionally, the literature on escalation of commitment has focused on social pressures and future expectations when explaining why this error occurs (as well as when it is likely to be most pervasive). Researchers have demonstrated that this decision error is caused by factors such as self-justification pressures (e.g., Bazerman, Giuliano, \& Appleman, 1984; Staw, 1976; Staw \& Fox, 1977) and the need to save face (Brockner, Rubin, \& Lang, 1981). The pressure to justify one's decision is then fueled by positive expectations regarding the future likelihood of success, resulting in a perceived need to "stay the course." Past experience (direct or vicarious) where people have been rewarded for persistence in the face of initial adversity helps maintain these positive expectations in the face of unambiguous negative feedback.

The traditional literature on escalation of commitment has not focused a great deal on individual differences (Moon, 2001b). However, when one considers the driving influence of selfjustification and unrealistic positive expectations on this process, it 
would seem that both anxiety and depression might be related to the manifestation of this decision error.

Turning first to anxiety, the need to justify past decisions (Staw, 1976) might be heightened for anxious individuals. Staw and Ross (1980) demonstrated the fact that individuals within organizations expected their leaders to "stay the course" in the face of negative information. Anxious individuals might be more sensitive to the social pressures embedded within escalation dilemmas to maintain the present course of action. This would be especially true to the extent that anxious individuals tend to be publicly self-conscious (Beck \& Clark, 1988). Eysenck (1992) refers to the tendency of anxious individuals to heighten their social scanning as "hypervigilance." Moreover, the degree to which anxious individuals tend to be hypervigilant and easily succumb to feelings of threat might make them especially susceptible to threat-rigidity effects (Staw, Sandelands, \& Dutton, 1981). Here, Staw et al. (1981) propose that as the level of perceived threat increases, individuals would tend to become "rigid" in their decision-making process, restrict their information processing, and therefore tend to continue on the same course of action. This would lead to a positive relationship between anxiety and escalation of commitment.

Whereas social pressures have implications for anxiety, the fact that escalation of commitment is fueled by unrealistically positive future expectations means that this aspect of the decision error might be inversely related to depression. Research on depression has shown that depressed individuals consistently underestimate their chances of success relative to nondepressed people (Wener \& Rehm, 1975). Those high in depression are also more likely to see their environment as being out of their control, and, hence, see a weak link between their current actions and their future success (Abramson \& Sackheim, 1977). Although in some situations these pessimistic perceptions may be detrimental to individual development, in the escalation of commitment context, this predisposition might actually be beneficial. Nesse (1991) views depression as having the positive effect of enhancing the ability of individuals to be more "brutally accurate" (p. 35) in their assessments. That is, Nesse does not view depressed individuals as underestimating their chance of success, but as not having the typical exuberance exhibited by other decision makers. The generally negative outlook for the future may neutralize the very influence (unrealistically high expectations) that 
typically maintains commitment to the course of action in the face of negative feedback. This would in turn result in less manifestation of this particular error among depressed, relative to nondepressed individuals.

Although it seems reasonable to predict a positive relationship between anxiety and escalation and a negative relationship between depression and escalation, one must reconcile these predictions with the fact that anxiety and depression are both facets of the same higher order construct (i.e., neuroticism). As facets of the same higher order factor, this implies that the two variables are positively related to each other. This means that the different and unique effect that each predictor has on the criterion is suppressed by the positive relationship between the predictors.

More formally, Cohen and Cohen (1975) define cooperative suppression as a condition where the amount of variance that is explained by the sum of the squared bivariate correlations $\left(r^{2} \times 1 y 1+r_{x 2 y 1}^{2}\right)$ is less than the amount of variance explained by the squared multiple correlation between the two predictors and the criterion (i.e. $R_{\mathrm{x} 1 \mathrm{x} 2 \mathrm{y} 1}^{2}$ ). Suppression is rare in multiple regression because, in most situations, predictors that are positively related to each other also tend to be related in the same direction to the criterion. Thus, in a simultaneous multiple regression where each predictor is entered in the same step, the squared multiple correlation between the two predictors and criterion is less than the sum of the squared bivariate correlations. Under these conditions, neither predictor shows a significant bivariate effect. In a simultaneous multiple regression where the suppressing effect is controlled, however, one sees that the squared multiple correlation is actually greater than the sum of the bivariate correlations, and the unique effects for each of the separate predictors can be documented.

One example of a suppression effect slightly different than those outlined by Cohen and Cohen (1975) was demonstrated by Brass (1985). He found that job characteristics related positively to employee satisfaction, while technical uncertainty was negatively related to employee satisfaction. However, job characteristics were positively related to technical uncertainty. Therefore, the shared variance between the two constructs (job characteristics and technological uncertainty) mutually suppressed each other's effect upon the criterion of interest (satisfaction). 
The conceptual arguments detailed above regarding the differential relationship between anxiety, depression, and commitment clearly fall under the general heading of cooperative suppression as delineated by Cohen and Cohen (1975) and mutual suppression advanced by Brass (1985). That is, although anxiety and depression are positively related to each other, they are differentially related to escalation of commitment. Thus, if one only examined the correlation between either anxiety or depression (or the higher order factor of neuroticism) and escalation of commitment, one would mistakenly conclude no effects where effects are present. To detect these effects, one would instead need to perform a simultaneous regression, where each of the facets is included, so that the suppressing effects could be removed. In line with these arguments, the hypothesis tested in this study is that in a simultaneous regression where both anxiety and depression are entered as predictors, anxiety will be positively related to escalation of commitment, whereas depression will be negatively related to escalation of commitment. Furthermore, these significant effects will be documented despite the lack of bivariate effects for either predictor or their higher order factor (i.e., Neuroticism).

\section{METHOD}

\section{Participants and Design}

One hundred and eighty-eight undergraduate students enrolled in a senior level management course at a large midwestern university participated in this study as an opportunity to gain extra credit toward their final grade. The experiment was conducted during class time in a controlled environment. For 116 respondents the data were collected on two separate occasions, approximately 1 month apart. Participants evaluated an escalation-of-commitment decision dilemma on the first occasion and completed the personality measures on the second occasion. For 72 of the respondents, the data were collected during a single time period.

\section{Decision-Making Task}

Students were asked to read, evaluate, and carefully answer questions related to a short scenario as if the scenario were actually true. The scenario was a slightly modified version of the well- 
established Arkes and Blumer (1985) radar-blank plane escalation scenario. In this scenario, the respondents are informed that they are vice president of operations for a midsized high-tech manufacturing firm. A large amount of time (32 months or 18 months) and money (9 million or 5 million) has already been spent on the project that is also behind schedule (either $50 \%$ or $10 \%$ complete).

A slight modification was used to create a cleaner manipulation of the negative framed situation required in escalation dilemmas within our study (consistent with the recommendations of McClelland, 1997 and confounds observed by Conlon \& Garland, 1993). Specifically, previous expenses (Staw, 1976) and project completion (Conlon \& Garland, 1993; Garland \& Conlon, 1998; Moon, 2001a) were manipulated to produce escalation scenarios that were "behind schedule." That is, we manipulated sunk-cost and completion such that there were higher levels of sunk-costs than level of completion (see Heath, 1995 for impact of budget allocation in escalation dilemmas).

The respondent was also informed that a competing firm had already begun marketing a similar product that took up less space and was easier to operate. The respondent decided (on a scale from 0 to 100 with ' 0 ' equal to absolutely no and 100 equal to absolutely yes) whether he or she would allocate the next $\$ 1$ million to continue the project.

\section{Control Variables}

Conscientiousness. Recently, Moon (2001b) found evidence that the other factor found to relate broadly to organizational criteria (conscientiousness) also had two facets that related differently in an escalation-of-commitment dilemma (duty and achievement-striving). In light of this, we had concerns of a potential spurious relationship between the facets of conscientiousness and neuroticism when predicting the escalation of commitment. This is based on neuroticism's substantial negative correlation with conscientiousness (Digman, 1997). Therefore, we controlled for the individual respondent's level of duty and achievement-striving when testing the facets of neuroticism. The items related to conscientiousness were collected at the same time as the facets and factors of neuroticism for both data samples. We used the Costa and McCrae 
(1992) facet level scales, which contained 8 items for duty and achievement striving.

\section{Independent Variables}

Neuroticism. The personality dimension of neuroticism was assessed using the NEO personality inventory (Costa \& McCrae, 1992). Although the neuroticism construct consists of six facets (anxiety, angry hostility, depression, self-consciousness, impulsiveness and vulnerability), of most importance to this study were the facets of anxiety and depression. The coefficient alpha reliabilities for overall neuroticism and the facets anxiety and depression were $.91, .82$, and .76, respectively. The coefficient alpha reliabilities for overall conscientiousness and the facets duty and achievement-striving were $.89, .64$ and .74 respectively. These reliability scores are consistent with those found by Costa and McCrae (1992) in a large sample study.

We understand that we ignored four other facets developed in the Costa and McCrae (1992) scale. However, they themselves argue against blindly accepting all six facets in any study, "Making sense of the 30 unrelated scales would be extremely difficult, and we have recommended that interpreters examine the facets domain by domain" (p. 18). Therefore, we focused on the two facets that comprise the tripartite model of neuroticism and that have received the most attention among clinical psychologists.

\section{Dependent Variables}

Level of Commitment. After reading the scenario, subjects indicated the probability from 0 to $100 \%(0=$ absolutely no, $50=$ don't know, $100=$ absolutely yes) that they would authorize the expenditure of the next $\$ 1$ million to continue the project. Due to the nonnormal distribution of the dependent variable, this variable was centered using the procedure outlined for moderate negative skewness (Tabachnick \& Fidell, 1996). This did not affect the results of the study in any meaningful way.

\section{RESULTS}

First, we tested whether the second set of respondents reacted differently to the scenario than the first. We found no difference in 


\section{Table 1}

Descriptive Statistics Associated With Personality Factors and Commitment

\begin{tabular}{lrrrrrrrrr}
\hline & $X$ & SD & \multicolumn{9}{c}{ Correlations } \\
\hline & & & 1. & 2. & 3. & 4. & 5. & 6. & 7. \\
1. Neuroticism & 2.67 & .49 & .91 & & & & & \\
2. Anxiety & 2.89 & .67 & $.76^{*}$ & .82 & & & & \\
3. Depression & 2.53 & .75 & $.86^{*}$ & $.59^{*}$ & .76 & & & \\
4. Conscientiousness & 3.54 & .44 & $-.41^{*}$ & -.06 & $-.42^{*}$ & .89 & & \\
5. Duty & 3.79 & .56 & $-.32^{*}$ & -.08 & $-.27^{*}$ & $.74^{*}$ & .64 & \\
6. Achievement Striving & 3.52 & .60 & $-.31^{*}$ & .01 & $-.37^{*}$ & $.83^{*}$ & $.52^{*}$ & .74 \\
7. Commitment & 3.53 & 2.41 & -.03 & .11 & -.05 & .09 & -.05 & .07 & - \\
\hline
\end{tabular}

Note. $N=188, * p<.05$. The coefficient alpha reliabilities for the scales are presented on the diagonal.

the average allocation decision across the two samples (mean sample $1=6.54$, mean sample $2=6.50, t=.12, p=n s$ ). Table 1 shows the descriptive statistics and simple bivariate correlations associated with the variables examined in this study. As seen in this table, neuroticism alone was not significantly correlated with commitment, $r=-.03, p=n s$ In addition, neither anxiety $(r=.11, p=n s)$ nor depression $(r=-.05, p=n s)$ is significantly correlated with commitment. The lack of a bivariate relationship between the facets of neuroticism and commitment is not surprising, given the predicted suppressive effects detailed in our hypotheses. Congruent with our prediction is the positive and reasonably strong correlation between anxiety and depression $(r=.59, p<.01)$.

To test our hypothesis, we performed a simultaneous regression where commitment served as the criterion, and anxiety and depression were entered as predictors. The results of this regression indicated that the two variables accounted for a statistically significant $3 \%$ of the variance (adjusted $R^{2}=.02$ ) in commitment, $F(2,185)=3.12, \quad p<.05$. In addition, we found statistically significant effects for each predictor. However, we predicted that anxiety would be positively related to commitment, while depression would be negatively related to commitment. As predicted, the 
standardized regression weights for the two were in the opposite direction, positive for anxiety $(\beta=.21, p<.05)$ but negative for depression $(\beta=-.17, p<.05)$. Figure 1 depicts the nature of the relationships between the bivariate correlations between the facets of neuroticism and decision commitment and the partialled correlations between the facets of neuroticism and decision commitment.

One concern we had was that of a spurious relationship between the facets of neuroticism and the facets of conscientiousness. Therefore, we tested whether the relationships between anxiety and depression remain after controlling for duty $(\beta=-.12, p=n s$, adjusted $R^{2}$ step $\left.=.01\right)$ and achievement striving $(\beta=.14, p=.05$, one tailed, adjusted $R^{2}$ step $\left.=.01\right)$. As before, both anxiety $(\beta=.20$, $p<.05$, adjusted $R^{2}$ step $\left.=.02\right)$ and depression $(\beta=-.18, p<.05$, one-tailed, adjusted $R^{2}$ step $=.01$ ) remained significant and in the predicted direction.

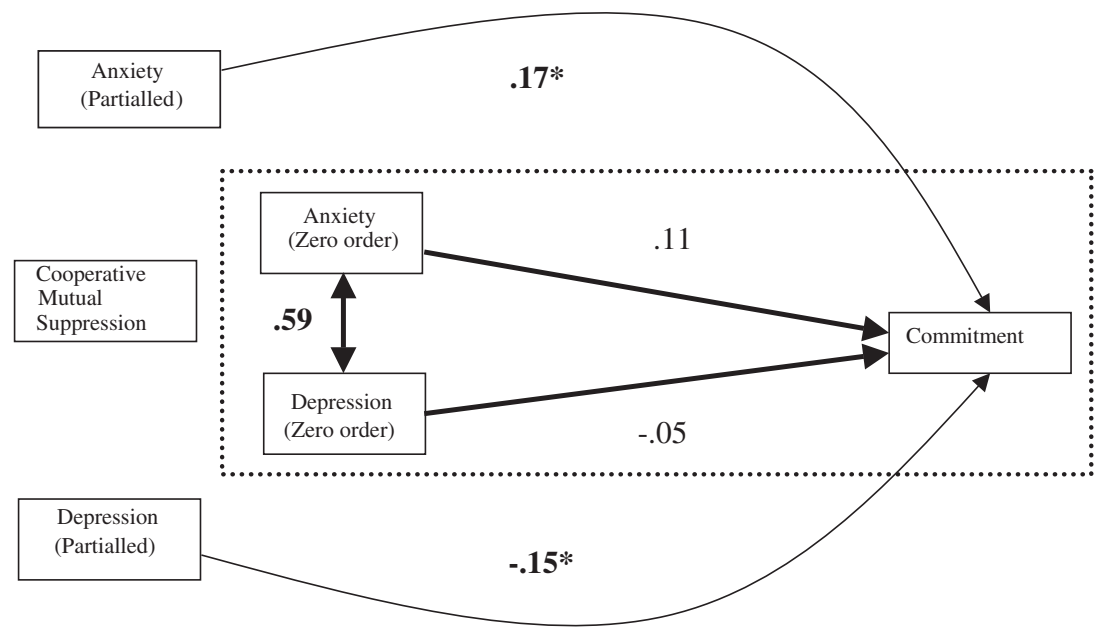

Note. $* p<.05$. The inside arrows depict the bivariate correlation with commitment while the outside arrows (outside of the dotted box) depict the partialled correlation between the predictors and criterion of interest.

Figure 1

Bivariate and partialled correlations between anxiety, depression and commitment 


\section{DISCUSSION}

In a recent meta-analysis, Salgado (1997) suggested that, in addition to conscientiousness, neuroticism should also be considered a valid and generalizable predictor of performance in work contexts. One recurrent limitation of the neuroticism construct has been its surprisingly low predictive ability of organizational criteria (Hurtz \& Donovan, 2000).

As we have shown, the broad construct of neuroticism, as used by applied psychologists, includes facets that have long been thought of as unique constructs. Consistent with these conceptual arguments, our empirical results, using a widely employed decision-making paradigm, indicate that the facets of anxiety and depression impact the decision maker's level of commitment (explaining 3\% of the variance), and do so in opposing ways. If one fails to distinguish between these two facets, and combines them to form an overall neuroticism score, this composite variable explains less than $1 \%$ of the variance in the same criterion. In general, this study supplements the growing literature on the trait-bandwidth personality debate, and just as others have called for a more narrow view of conscientiousness (Ashton, 1998; Hough, 1992), it implies that we may need to take a similar approach to neuroticism (Hampson, John, \& Goldberg, 1986).

There are a few limitations to our study that future studies might address. First, our effects were modest (a relatively small level of variance explained (adjusted $R^{2}=.03$ ) and the $p$ is significant at .05 on a one tailed test for depression after controlling for duty and achievement striving). In fairness, it is quite safe to assume, based on several meta-analyses (Barrick \& Mount, 1991; Hurtz \& Donovan, 2000) that the actual observed effect size of neuroticism and facets of neuroticism across hundreds of studies has been consistently modest. Our findings are actually consistent with the effect sizes found in the meta-analyses. Also, we hope that, based on our mutual suppression hypothesis, the explanatory power will be less compelling than the unique relational model is interesting. We hope our discussion section outlines several potential streams of future research that might find more robust, or consistent, findings.

First, we suspect that most, if not all, of our sample fell below what would be viewed as "clinical" levels of depression and anxiety. It would be interesting to determine if those individuals who where 
clinically depressed or anxious would react differently to our task. Second, we acknowledge that we use a single measure of neuroticism with facets, anxiety and depression, that are currently used by organizational researchers rather than by clinical scientists. Future research can replicate our findings using clinically depressed or anxious individuals and/or different measures of anxiety and depression.

In conducting future research related to our findings, we feel that there are several opportunities for research relating neuroticism and its facets to organizational criteria. We suspect that the differential impact of anxiety and depression is not limited to decision commitment but might be important in a wide range of organizational contexts. For example, organizational socialization is the longest and most complex aspect of organizational entry (Wanous, 1992) as newcomers learn the ropes (Van Maanen \& Schein; 1979). Much of the research on organizational socialization has been concerned with the process through which an individual becomes acclimated to new surroundings (Chao, O'Leary-Kelly, Wolf, Klein, \& Gardner, 1994). Chao et al. note that, recently, the content of socialization (i.e., learning social features of an organization such as its history, politics, language, people, and organizational goals/ values, as well as job-related dimensions such as performance and proficiency) has been implicated with the successful socialization of new employees. Both E. W. Morrison (1993) and Ostroff and Kozlowski (1992) have demonstrated the extent to which newcomer feedback/information seeking is important for successful socialization. We suspect that the broad trait of neuroticism will negatively influence the socialization process, but that the narrow traits of depression and anxiety reveal more fine-grained understanding of dysfunctional socialization.

On the one hand, Coyne (1976a; 1976b) developed an interpersonal model of depression wherein he proposed that individuals who were depressed tended to induce negative reactions from others by their habitual need for reassurance. Joiner and Metalsky (1995) confirmed the interpersonal nature of depression by finding that depressed college roommates engaged in more negative feedback and reassurance seeking. This led to higher subsequent rejection rates. Therefore, future studies can explore the possibility that the dysfunctional interpersonal nature of depression would lead depressed individuals to seek more feedback, but that this feedback would be dysfunctional. 
On the other hand, anxious individuals might actually seek less feedback to the extent that they are adverse to interpersonal exchanges. Clark and Arkowitz (1975) would view this as social anxiety or Ingraham and Wright (1987) as the aversion to interpersonal interactions. In sum, although the broad trait of neuroticism might be predictive of individuals who struggle with the socialization process, depression might be related to dysfunctional feedback seeking while anxiety might be related to dysfunctional feedback avoidance.

Similarly, anxiety and depression may differentially influence the degree to which individuals respond to feedback. This may be especially true to the extent that feedback comes from multiple sources (London \& Smither, 1995). The hypervigilance (Eysenck, 1992) associated with anxiety might lead individuals to overrespond to feedback, while feelings of uncontrollability (Abramson \& Sackheim, 1977) and negative perceptions of success (Wener \& Rehm, 1975) might lead depressed individuals to underrespond.

Anxiety and depression might also differentially affect an individual's propensity to turnover (March \& Simon, 1958). The rigidity demonstrated by anxious individuals within escalation of commitment dilemmas may extend to those same individuals demonstrating reluctance to leave their place of employment. The propensity of depressed individuals to de-escalate their commitment in the face of negative information may extend to those same individuals demonstrating a propensity to leave their place of employment. In all of the above examples (feedback seeking, feedback acceptance, and turnover), we propose similar opposite relationships between the facets of a tripartite model of neuroticism and organizational criteria as demonstrated in the decision-making literature. Future studies can extend, refine, or refute our assertions.

This is not to say that there might not be instances wherein the two facets of neuroticism act in concert rather than against each other, and measurement at the broad level might be appropriate. For example, the military often finds recruitment and training of soldiers for their more exclusive units to be a difficult and costly enterprise. In the Army this might include recruitment for Ranger battalions and Special Forces units. Successful completion of training is difficult, and the percentage of individuals who fail has been historically high. It is logical that both low levels of anxiety 
(able to handle the external stress associated with training) and low levels of depression (able to keep a positive attitude in trying circumstances) are important and positive predictors of an individual's success in these advanced units.

Certainly, the laboratory nature of this research serves as a limiting factor when it comes to generalizing these results to applied contexts (Tetlock, 1990). However, we think that such criticism is mitigated by the fact that this study focused less on the responses given to the instrument and more on the relationship between these responses and an individual's personality traits that have not been demonstrated in any organizational setting. In addition, we think that because the respondents were from a business capstone class, the distribution of personality would actually be quite similar to the personality of a majority of individuals working in business-related organizations. In addition, the sunk-cost instrument used in this study has been used in a series of published papers exploring the effects of sunk-costs and completion (Arkes \& Blumer, 1985; Conlon \& Garland, 1993; Garland \& Conlon, 1998).

It is hoped that this study will serve as a catalyst for future research that examines these and other important differences between facets associated with the broad trait of neuroticism. At the very least, we hope that this study will alert applied psychologists to the long established difference between anxiety and depression established by clinical psychologists. In the rush to commit ourselves to the Five-Factor Model of personality, we should not naively apply a unidimensional treatment of neuroticism. This may be a depressing conclusion, compared to the promise of a second, broad, generalizable work-related personality trait (Salgado, 1997). However, as we have seen, when depression counters otherwise unrealistic future expectations, the ability to de-escalate one's commitment in the face of negative information is not altogether a bad thing.

\section{REFERENCES}

Abramson, L. Y., \& Sackeim, H. A. (1977). A paradox of depression: Uncontrollability and self-blame. Psychological Bulletin, 84, 838-851.

Arkes, H. R., \& Blumer, C. (1985). The psychology of sunk cost. Organizational Behavior and Human Decision Processes, 35, 124-140. 
Ashton, M. C. (1998). Personality and job performance: The importance of narrow traits. Journal of Organizational Behavior, 19, 289-303.

Barrick, M. R., \& Mount, M. K. (1991). The big five personality dimensions and job performance: A meta-analysis. Personnel Psychology, 44, 1-26.

Barrick, M. R., Mount, M. K., \& Judge, T. A.(in press) Personality and performance at the beginning of the new millennium: What do we know and where do we go next? International Journal of Selection and Assessment.

Barrick, M. R., Stewart, G. L., Neubert, M. J., \& Mount, M. K. (1998). Relating member ability and personality to work-team processes and team effectiveness. Journal of Applied Psychology, 83, 377-391.

Bazerman, M. H., Giuliano, T., \& Appelman, A. (1984). Escalation of commitment in individual and group decision making. Organizational Behavior and Human Performance, 33, 141-152.

Beck, A. T. (1967). Depression: Clinical, experimental, and theoretical aspects. New York: Harper \& Row.

Beck, A. T. (1976). Cognitive therapy and the emotional disorders. New York: New American Library.

Beck, A. T., \& Clark, D. A. (1988). Anxiety and depression: An information processing perspective. Anxiety Research, 1, 23-36.

Brass, D. J. (1985). Technology and the structuring of jobs: Employee satisfaction, performance, and influence. Organizational Behavior and Human Decision Processes, 35, 216-240.

Brockner, J., Rubin, J. Z., \& Lang, E. (1981). Face saving and entrapment. Journal of Experimental Social Psychology, 17, 68-79.

Cattell, R. B. (1947). Confirmation and clarification of primary personality factors. Psychometrika, 12, 197-220.

Cattell, R. B. (1956). Second-order personality factors in the questionnaire realm. Journal of Consulting Psychology, 20, 411-418.

Chao, G. T., O'Leary-Kelly, A. M., Wolf, S., Klein, H. J., \& Gardner, P. D. (1994). Organizational socialization: Its content and consequences. Journal of Applied Psychology, 79, 730-743.

Clara, I. P., Cox, B. J., \& Enns, M. W. (2001). Confirmatory factor analysis of the depression-anxiety-stress scales in depressed and anxious patients. Journal of psychopathology and behavioral assessment, 23, 61-67.

Clark, J. V., \& Arkowitz, H. (1975). Social anxiety and the self-evaluation of interpersonal performance. Psychological Reports, 36, 211-221.

Clark, L. A., \& Watson, D. (1991). Tripartite model of anxiety and depression: Psychometric evidence and taxonomic implications. Journal of Abnormal Psychology, 100, 316-336.

Cohen, J., \& Cohen, P (1975). Applied Multiple Regression/Correlation Analysis for the Behavioral Sciences. New York: John Wiley \& Sons.

Colquitt, J. A., \& Simmering, M. J. (1998). Conscientiousness, goal orientation, and motivation to learn during the learning process: A longitudinal study. Journal of Applied Psychology, 83, 654-665.

Conlon, D. E., \& Garland, H. (1993). The role of project completion information in resource allocation decisions. Academy of Management Journal, 36, $402-413$. 
Costa, P. T., \& McCrae, R. R. (1985). The NEO Personality Inventory Manual. Odessa, FL: Psychological Assessment Resources.

Costa, P. T., \& McCrae, R. R. (1992). Revised NEO Personality Inventory (NEOPIR): Professional Manual. Psychological Assessment Resources, Inc.

Coyne, J. C. (1976a). Depression and the response to others. Journal of Abnormal Psychology, 85, 186-193.

Coyne, J. C. (1976b). Toward an interactional description of depression. Psychiatry, 39, 28-40.

Digman, J. M. (1990). Personality structure: Emergence of the five-factor model. Annual Review of Psychology, 41, 417-440.

Digman, J. M. (1997). Higher-order factors of the big five. Journal of Personality and Social Psychology, 73, 1246-1256.

Digman, J. M., \& Takemoto-Chock, N. K. (1981). Factors in the natural language of personality: Re-analysis, comparison, and interpretation of six major studies. Multivariate Behavioral Research, 16, 148-170.

Eysenck, M. W. (1992). Anxiety: The cognitive perspective. Hover, UK: Lawrence Erlbaum.

Fiske, D. W. (1949). Consistency of factorial structures of personality ratings from different sources. Journal of Abnormal and Social Psychology, 44, 329-344.

Freud, S. (1930). Civilization and its discontents. New York: Norton.

Garland, H., \& Conlon (1998). Too Close to quit: The role of project completion in maintaining commitment. Journal of Applied Social Psychology, 28, 2025-2048.

Goldberg, L. R. (1992). The development of markers for the big-five factor structure. Psychological Assessment, 4, 26-42.

Goldberg, L. R. (1993). The structure of phenotypic personality traits. American Psychologist, 48, 26-34.

Hampson, S. H., John, O. P., \& Goldberg, L. R. (1986). Category breadth and hierarchical structure in personality: Studies in asymmetries in judgements of trait implications. Journal of Personality and Social Psychology, 51, 37-54.

Heath, C. (1995). Escalation and De-escalation of commitment in response to sunk-costs: The role of budgeting in mental accounting. Organizational Behavior and Human Decision Processes, 62, 38-54.

Hogan, R. (1983). A socioanalytical theory of personality. In M. M. Page (Ed.), Personality-current theory and research: Nebraska symposium on motivation (pp. 55-89). Lincoln: University of Nebraska Press.

Hogan, R. T., \& Hogan, J. (1992). Hogan Personality Inventory Manual. Tulsa, OK: Hogan Assessment Systems.

Horney, K. (1937). The Neurotic personality of Our Time. New York: Norton.

Horney, K. (1945). Our Inner Conflicts. New York: Norton.

Hough, L. M. (1992). The "big five" personality variables - construct confusion: Description versus prediction. Human Performance, 5, 139-155.

Hough, L. M., Eaton, N. K., Dunnette, M. D., Kamp, J. D., \& McCloy, R. A. (1990). Criterion-related validities of personality constructs and the effect of response distortion on those validities. Journal of Applied Psychology, 75, $581-595$. 
Hurtz, G. M., \& Donovan, J. J. (2000). Personality and Job performance: The big five revisited. Journal of Applied Psychology, 85, 869-879.

Ingraham, L. J., \& Wright, T. L. (1987). A social relations model test of Sullivan's Anxiety Hypothesis. Journal of Personality and Social Psychology, 52, 1212-1218.

John, O. P. (1989). Towards a taxonomy of personality descriptors. In D. M. Buss, \& N. Cantor (Eds.), Personality psychology: Recent trends and emerging directions (pp. 261-271). New York: Springer-Verlag.

Joiner, T. E., \& Metalsky, G. I. (1995). A prospective test of an integrative interpersonal theory of depression: A naturalistic study of college roommates. Journal of Personality and Social Psychology, 69, 778-788.

Kremen, A. M. (1996). Depressive tendencies and susceptibility to anxiety: Differential personality correlates. Journal of Personality, 64, 209-242.

Lepine, J. A., Hollenbeck, J. R., Ilgen, D. R., \& Hedlund, J. (1997). Effects of individual differences on the performance of hierarchical decision-making teams: Much more than g. Journal of Applied Psychology, 82, 803-811.

London, M., \& Smither, J. W. (1995). Can multi-source feedback change perceptions of goal accomplishment, self-evaluations, and performance-related outcomes? Theory-based applications and directions for research. Personnel Psychology, 48, 803-838.

March, J. G., \& Simon, H. A. (1958). Organizations. New York: Wiley.

McClelland, G. H. (1997). Optimal design in psychological research. Psychological Methods, 2, 3-19.

McNamara, G., Moon, H., \& Bromiley, P. (2002) Banking on commitment: Intended and unintended consequences of an organization's attempt to attenuate irrational commitment. Academy of Management Journal, 45, 443-452.

McNamara, R. S., \& VanDeMark, B. (1995). In retrospect: The tragedy and lessons of Vietnam. New York: Times Books.

Mendels, J., Weinstein, N., \& Cochrane, C. (1972). The relationship between depression and anxiety. Archives of General Psychiatry, 27, 649-653.

Moon, H. (2001a). Looking forward and looking back: Integrating completion and sunk-cost effects within an escalation of commitment progress decision. Journal of Applied Psychology, 86, 104-113.

Moon, H. (2001b). The two faces of conscientiousness: Duty and Achievement striving in escalation of commitment dilemmas. Journal of Applied Psychology, 86, 533-540.

Morrison, E. W. (1993). Longitudinal study of the effects of information seeking on newcomer socialization. Journal of Applied Psychology, 77, 926-940.

Mount, M. K., \& Barrick, M. R. (1995). The big five personality dimensions: Implications for research and practice in human resource management. Research in Personnel and Human Resources Management, 13, 153-200.

Mount, M. K., \& Barrick, M. R. (1998). Five reasons why the "big five" article has been frequently cited. Personnel Psychology, 51, 849-857.

Nesse, R. M. (1991). What good is feeling bad? The evolutionary benefits of psychic pain. The Sciences, 31, 30-37.

Neuman, G. A., \& Wright, J. (1999). Team effectiveness: Beyond skills and cognitive ability. Journal of Applied Psychology, 84, 376-389. 
Norman, W. T. (1963). Toward an adequate taxonomy of personality attributes. Journal of Abnormal and Social Psychology, 66, 574-583.

Ostroff, C., \& Kozlowski, S. W. J. (1992). Organizational socialization as a learning process: The role of information acquisition. Personnel Psychology, 45, 849-874.

Paunonen, S. V., \& Ashton, M. C. (2001). Big five factors and the prediction of behavior. Journal of Personality and Social Psychology, 81, 524-539.

Paunonen, S. V., \& Jackson, D. N. (2000). What is beyond the Big Five? Plenty!. Journal of Personality, 68, 821-835.

Paunonen, S. V., Rothstein, M. G., \& Jackson, D. N. (1999). Narrow reasoning about the use of broad personality measures for personnel selection. Journal of Organizational Behavior, 20, 389-405.

Ross, J., \& Staw, B. M. (1993). Organizational escalation and exit: Lessons from the Shoreham Nuclear Power Plant. Academy of Management Journal, 36, 701-732.

Salgado, J. F. (1997). The five factor model of personality and job performance in the European community. Journal of Applied Psychology, 82, $30-43$.

Simonson, I., \& Staw, B. M. (1992). De-escalation strategies: A comparison of techniques for reducing commitment to losing courses of action. Journal of Applied Psychology, 77, 419-426.

Stavrakaki, C., \& Vargo, B. (1986). The relationship of anxiety and depression: A review of the literature. British Journal of Psychiatry, 149, 7-16.

Staw, B. M. (1976). Knee deep in the big muddy: A study of escalating commitment to a chosen course of action. Organizational Behavior and Human Performance, 16, 27-44.

Staw, B. M. (1997). The escalation of commitment: An update and appraisal. In Zur Shapira (Ed.) Organizational Decision Making (pp. 191-215). New York: Cambridge University Press.

Staw, B. M., \& Fox, F. V. (1977). Escalation: The determinants of commitment to a chosen course of action. Human Relations, 30, 431-450.

Staw, B. M., \& Ross, J. (1980). Commitment in an experimenting society: A study of the attribution of leadership from administrative scenarios. Journal of Applied Psychology, 65, 249-260.

Staw, B. M., Sandelands, L. E., \& Dutton, J. E. (1981). Threat-rigidity effects in organizational behavior: A multilevel analysis. Administrative Science Quarterly, 26, 501-524.

Tabachnick, B. G., \& Fidell, L. S. (1996). Using Multivariate Statistics. New York: HarperCollins College Publishers.

Tetlock, P. E. (1990). Accountability: The neglected social context of judgement and choice. In L. L. Cummings, \& B. M. Staw (Eds.), Information and cognition in organizations (pp. 169-204). Greenwich, CT: JAI Press.

Tett, R. P., Jackson, D. N., \& Rothstein, M. (1991). Personality measures as predictors of job performance: A meta-analytic review. Personnel Psychology, 44, 703-742.

Tupes, E. C., \& Christal, R. E. (1961). Recurrent personality factors based on trait ratings. USAF ASD Tech. Rep, no. 61-97. 
Van, Maanen J. V., \& Schein, E. H. (1979). Toward a theory of Organizational Socialization. In B. M. Staw, \& L. L. Cummings (Eds.), Research in Organizational Behavior (Vol. 1, pp. 209-264). Greenwich, CT: JAI Press.

Wanous, J. P. (1992). Organizational Entry. New York: Addison Wesley.

Wener, A. E., \& Rehm, L. P. (1975). Depressive affect: A test of behavioral hypotheses. Journal of Abnormal Psychology, 84, 221-227.

Wetherell, J. L., Gatz, M., \& Pedersen, N. L. (2001). A longitudinal analysis of anxiety and depressive symptoms. Psychology and Aging, 16, 187-195. 